\title{
PREVENTION AND TREATMENT OF ORAL MUCOSITES IN PATIENTS SUBMITTED TO CHEMOTHERAPY AND RADIOTHERAPY: WHAT DOES THE DENTAL SURGEON NEED TO KNOW? - A LITERATURE REVIEW
}

\section{Lorena Lopes de Morais Nametala}

Student at the Multidisciplinary Center for Intensive Dentistry (CEMOI), Rio de Janeiro, RJ, Brazil.

\section{Milena Monteiro dos Santos}

Student at the Multidisciplinary Center for Intensive Dentistry (CEMOI), Rio de Janeiro, RJ, Brazil.

\section{Carla Marcela dos Santos Esteves}

Student at the Multidisciplinary Center for Intensive Dentistry (CEMOI), Rio de Janeiro, RJ, Brazil.

\section{Bianca Santana}

Doctor at the Pediatric Oncology Service of the National Cancer Institute (INCA), Rio de Janeiro, RJ, Brazil.

\section{Marcela Dias Lopes Martins}

Doctor at the Palliative Care Service of the National Cancer Institute (INCA), Rio de Janeiro, RJ, Brazil.

\section{Josiane Costa Rodrigues de Sá}

Professor at the Multidisciplinary Center for Intensive Dentistry (CEMOI), Rio de Janeiro, RJ, Brazil.

\section{Rodrigo Figueiredo de Brito Resende}

Professor at the Multidisciplinary Center for Intensive Dentistry (CEMOI), Rio de Janeiro, RJ, Brazil.

Institution in which the work was carried out: Multidisciplinary Center for Intensive Dentistry (CEMOI), Rio de Janeiro, RJ, Brazil and National Cancer Institute (INCA), Rio de Janeiro, RJ, Brazil.

Category: Literature review

Lorena Lopes de Morais Nametala

Macedo Sobrinho Street, 21 - Humaitá, Rio de Janeiro - RJ, Brazil - 22271-080

E-mail:lorenalopesodonto@hotmail.com 


\begin{abstract}
Chemotherapy and radiotherapy alone or together are widely used as protocols in the treatment of cancer patients. However, they can induce a type of lesion in the oral cavity called mucositis. This type of injury is one of the most frequent sequelae seen in patients undergoing cancer treatment, being commonly reported due to pain and difficulty in eating. Currently, there are still no specific and effective protocols for its prevention and treatment. The aim of this study is to conduct a literature review, seeking to present oral mucositis, its etiopathogenesis, clinical characteristics and some therapeutic strategies proposed today, emphasizing the importance of the insertion and performance of the dentist in the oncology team. Within the therapeutic modalities studied, low-level laser therapy stands out as an efficient alternative both in the prevention and in the treatment of oral mucositis, where it presents itself as a low-cost, non-traumatic treatment with excellent described results. in literature.
\end{abstract}

KEYWORDS: Dental Surgeon. Mucositis. Chemotherapy. Radiotherapy.

\title{
INTRODUCTION
}

Oral mucositis (OM) was described in 1980 as an inflammation of the oral mucosa, with extremely painful, erythematous and ulcerated lesions (Ribeiro Júnior et al., 2010; Daugèlaitė et al., 2019; Marques et al., 2020). This type of injury appears as a side effect in cancer patients, who have undergone chemotherapy treatments, radiotherapy to the head and neck and hematopoietic stem cell transplantation. Studies indicate that approximately 85 to $100 \%$ of patients treated with chemotherapy or radiotherapy develop mucositis to varying degrees depending on the radiation dose, the drug used, and the form of administration (Menezes et al., 2014).

Usually, this type of lesion appears after the period of seven days from the beginning of antineoplastic treatment, manifesting itself as painful lesions that can cause dysphagia, changes in taste, weight loss and secondary infections (Ribeiro et al. 2008; Santos et al. 2009 ; Daugèlaitė et al., 2019). These complications can delay or prevent the continuation of treatments requiring the use of analgesics or even nutrition via enteral or parenteral routes (Ribeiro et al. 2008; Santos et al. 2009). All of this has a direct impact on patient survival (Santos et al. 2009; Miranda et al. 2016; Oliveira et al., 2018).

Radiotherapy and chemotherapy initially cause cell damage and generate free radicals, resulting in necrosis of the basal epithelial cells. It is followed by an increase in inflammatory factors that increase cell death. With the exposure of the conjunctiva, ulcers appear. As a result, there is an increase in the adhesion of fungi, viruses and bacteria already present in the oral microbiota, which can aggravate the lesions, the pain and the 
risk of sepsis to the patient (Florentino et al., 2015; Daugèlaite et al., 2019; Marques et al., 2020). The evolution of oral mucositis is complex, being influenced by other complications such as xerostomia, dysgeusia, adenophagia and opportunistic infections such as candidosis (Ribeiro Júnior et al., 2010).

To date, there is no standard therapy in the literature for its prevention and treatment. Preventively, mouthwashes with $0.12 \%$ chlorhexidine gluconate, cryotherapy, laser therapy and use of natural agents such as sage, myrrh, glutamine and glycerin are suggested (Albuquerque et al., 2007; Santos et al. 2009; Ribeiro Júnior et al., 2010; Florentino et al., 2015).

\section{LITERATURE REVIEW}

Cancer today is one of the most prevalent diseases in the world. Thus, an early diagnosis is so necessary to enable an effective treatment of chemotherapy, radiotherapy, surgery or in combination (Menezes et al., 2014; Florentino et al., 2015).

One of the most significant side effects of antineoplastic treatments is MO. This generic term of "inflammation in the mucosa" has been used in the scientific literature to indicate injuries resulting from cytotoxic effects caused by chemotherapy or radiotherapy in the oral tract (Garcez et al., 2012). The most affected areas are the floor of the mouth, the lateral border of the tongue, the lingual belly, the cheek mucosa and the soft palate (Florentino et al., 2015).

The National Cancer Institute (NCI) has published common terminology criteria for adverse events, including subjective and objective scales for OM: Grade 1 - mucosal erythema; Grade 2 - irregular or pseudomembranous ulcerations; Grade 3 - ulcerations or pseudomembranes at confluents, bleeding with minor trauma; Grade 4 - tissue necrosis, significant spontaneous bleeding; life-threatening consequences; and Grade 5 - death (Daugèlaitè et al., 2019).

The risk for the appearance, severity and duration of OM take into account the type of treatment proposed, age, sex, genetic predisposition, oral health and hygiene, oral microflora, normality and secretory function of saliva, food, exposure to alcohol and tobacco, comorbidities (Albuquerque et al., 2007; Menezes et al., 2014) the location to 
be irradiated, the rate of radiation dose accumulation, the specific chemotherapy agent and their dose schedules (Menezes et al., 2014), habits breathing through the mouth (Ribeiro et al., 2008).

OM when caused by chemotherapy is associated with specific pharmacological agents (Methotrexate, S. Fluoruoracil, Bleomycin, Doxorubicin, Cisplatin, Vinblastine and Vincristine). When caused by radiotherapy, it depends on the type of radiation, volume of irradiated tissue, daily and total doses, fractionation scheme (Santos et al., 2009).

The appearance of OM and its clinical evolution depend on the patient's individual response to the protocol used (oral toxicity of chemotherapy, accumulated radiation dose, irradiated field and association of radiotherapy with chemotherapy) (Florentino et al., 2015). When induced by chemotherapy, it lasts an average of one week and resolves in 21 days after the use of chemotherapy drugs. Radiotherapy remains for two weeks after the end of the treatment application (Menezes et al., 2014).

\section{PREVENTION}

Many studies emphasize the importance of oral health to reduce complications of cancer treatment. A detailed stomatological evaluation and the institution of oral care is necessary before, during and after cancer therapy (Valduga et al., 2018).

In the first dental approaches, which must be performed before the beginning of antineoplastic treatment, treatment of carious lesions, control of bacterial plaque and removal of orthodontic appliances should be performed (Florentino et al., 2015; Oliveira et al., 2018). Elements with inflammatory, infectious or pulp impairment must be treated or extracted and must be submitted to radiographic exams (Florentino et al., 2015) in order to improve the patient's general health and reduce possible complications. (Ribeiro Júnior et al., 2010; Menezes et al., 2014). In this evaluation, pathologies such as pemphigoids, lichen planus, leukoplakia and other lesions that can be confused or altered with the presence of OM must also be observed (Ribeiro Júnior et al., 2010). Edentulous patients should also be evaluated. Removable prostheses must be evaluated for their adaptation, retention and stability, seeking to remove possible sources of trauma. Patients 
should be advised about possible discontinuation of use if necessary to avoid mechanical trauma. The patient should not sleep with the prosthesis and it should be immersed in half an American glass with water and a teaspoon of sodium bicarbonate, covering the glass with a paper towel (Menezes et al., 2014; Lopes et al., 2016 ).

The patient should be given an intense motivation regarding oral hygiene. This care is extremely important in reducing infections and preventing severe oral mucositis. The use of soft and non-traumatic brushes, dental floss, as tolerated and assessing the patient's hematological condition, toothpaste with fluoride and non-alcoholic rinses is recommended (Albuquerque et al., 2007). Cleaning the tongue should be advised, as it improves the stimulation of the taste receptors and improves the salivary stimulus (Ribeiro Júnior et al., 2010).

Cryotherapy, using ice, is a low-cost, risk-free form of prevention that is easy to apply and highly effective. Promotes local vasoconstriction, decreasing blood flow to the oral mucosa, reducing cell damage. Prevents the appearance of new lesions and induces pain relief. It is a practice established in the guidelines for mucositis care of the Multinational Association of Supportive Care in Cancer and International Society of Oral Oncology (MASCC / ISOO) 2014 (Lopes et al., 2016).

Another preventive care used is the use of the macrophage colony stimulating factor - granulocyte (GM - CSF) which is a cytokine that induces mucosal protection during the performance of antineoplastic treatment that has shown controversial results, requiring additional and detailed studies (Albuquerque et al., 2007; Santos et al. 2009).

Palifermin (keratinocyte growth factor) has been used for the reduction and incidence of oral mucositis with good clinical results (Ribeiro RA et al., 2008; Santos et al., 2009; Miranda et al. 2016; Daugèlaitè et al., 2019). It induces cell proliferation, increasing the thickness of the epithelium, reducing the damage to DNA caused by antineoplastic therapies. It promotes the increase of detoxifying enzymes that protect the tissue from the action of oxidizing compounds, decreasing the levels of inflammatory cytokines and apoptosis (Santos et al., 2009).

Anti-inflammatory medications such as benzidamine in the oral rinse reduced the frequency of grade III mucositis in patients who used it (Hong et al. 2019). Studies have evaluated the use of mild mouthwash with diagrams using saline or sodium bicarbonate REVISTA FLUMINENSE DE ODONTOLOGIA - ANO XXVIII - No 56 - Julho / Dezembro 2021 
to prevent OM, which may reduce its severity. Chlorhexidine has been extensively studied, some studies have shown its effectiveness, observing a decrease in OM grade III and IV and its duration was shorter (Daugèlaite et al., 2019) and others say they have no additional benefit in preventing OM. In fact, they reported greater discomfort, changes in taste and tooth color (Hong et al., 2019).

Royal jelly with benzidamine hydrochloride and nystatin washes were evaluated and resulted in a faster recovery of OM grade III, II and I. In another study, the use of lactobacilli brevis (CD2) was evaluated and the studies showed that the MO of any degree developed less frequently and patients used less analgesics for pain relief. The use of zinc promoted a lower frequency of OM with its use (Hong et al., 2019).

Preventive nutritional care includes eating cold food or at room temperature; avoid irritating foods and give preference to foods that are easy to chew and swallow (Lopes et al., 2016).

Low-power laser therapy to prevent OM, at wavelengths between 630-660 nm, was of great value for patients undergoing hematopoietic cell transplantation and radiotherapy. In patients undergoing chemotherapy, no guideline was possible due to the absence of randomized control and the significant variability of photomodulatory therapy parameters (Hong et al., 2019).

\section{TREATMENT}

It is based on prevention and palliative care, aiming at pain relief and preventing the emergence of secondary infections. Therefore, many substances have been studied to reduce the severity of mucositis, such as pain relievers, vitamins $A, D, Z n$, mouthwashes, local anesthetics, laser therapy, among others, however, without absolute effectiveness (Oliveira et al., 2018).

Maintaining hygiene before, during and after treatment will reduce the risk of dental complications, including infections, cavities, gingivitis and osteoradionecrosis (Menezes et al., 2014). Mucin-based saliva substitutes or artificial saliva can be used as a palliative in xerostomia (Ribeiro Júnior et al., 2010; Oliveira et al., 2018). 
An option widely used in the treatment of $\mathrm{OM}$ is cryotherapy. It is based on temporary mucosal vasoconstriction, with the use of ice, to reduce the exposure of the epithelium to cytotoxic agents such as flourouracil (5-FU), a drug widely used in the treatment of cancer. Cryotherapy is commonly performed during chemotherapy infusions, in a period that varies between 30 and 45 min. Simple treatment with good results (Ribeiro Júnior et al., 2010; Daugèlaitė et al., 2019). It can be used emphatically in the inflammatory phase of Mucositis already installed, before the appearance of ulcers (Ribeiro Júnior et al., 2010).

The use of antifungals, such as nystatin, clotrimazole, cytoconazole, fluconazole, is suitable for promoting local or systemic treatment of a fungal infection that may arise as an opportunist. Greater acceptance of fluconazole was observed due to its more pleasant flavor and because it is a single dosage (Ribeiro Júnior et al., 2010).

For treatment in cases where symptoms are influencing patients' quality of life, local anesthetics such as viscous lidocaine, tetracycline gel and diclonine hydrochloride are used. In severe cases, centrally acting analgesics such as morphine, codeine and tramadol can be used (Ribeiro Júnior et al., 2010).

Diphenhydramine hydrochloride, an antihistamine, can be used as mouthwash diluted in water. Benzidamine hydrochloride is also effective in topical pain control, due to its anti-inflammatory, antimicrobial and anesthetic action, (Ribeiro Júnior et al., 2010; Menezes et al., 2014). Mouthwashes with corticosteroids can be used to relieve the inflammatory process of OM (Ribeiro Júnior et al., 2010).

Natural agents such as chamomile, sage and myrrh, for their antimicrobial action, can be used in the form of mouthwashes, four times a day (Ribeiro Júnior et al. 2010, Miranda et al., 2016).

Mouthwashes with Gelclair bioadhesive gel (polyvinylpyrrolidone and sodium hyaluronate) form a film on the oral mucosa, promoting physical protection of ulcers, providing rapid relief. However, clinical studies are needed to prove its effectiveness. In addition, there is the medication OraMedic (Aloe Vera which has a healing, antiinflammatory and bactericidal action; and Maltodextrin which forms a protective film) (Ribeiro et al., 2008). 
The use of laser has indicated great effectiveness in reducing the severity of OM. The functionality of laser therapy in cancer patients is known, promoting biological effects through photophysical and biochemical processes, increasing cellular metabolism. The laser acts as an anti-inflammatory, analgesic and healing wound, stimulating its mitochondrial activity (Hong et al., 2019). Its mechanism of action is the photostimulation of chromophores that induce an increase in the production of adenosine in the cells of the oral mucosa, thus accelerating cellular metabolism. This mechanism increases the response of fibroblast production, which is associated with a shorter healing time (Florentino et al., 2015).

\section{DISCUSSION}

Much has been researched about which care is most effective in the prevention and treatment of OM. There is no consensus on a protocol and, therefore, several methods and substances researched are used empirically and palliative. All research efforts are important given the high prevalence of OM in cancer patients, in search of a specific, safe and effective protocol (Hong et al. 2019).

Through this literature review, it was observed that among the measures proposed in the studies to prevent and treat OM, resulting from antineoplastic treatment, they are centered on the elaboration of an oral care program, emphasizing that when done by a dental surgeon trained, becomes more efficient and allows interventions aimed at the management and control of pain, identification of infections, thus obtaining a more adequate monitoring with more effective results (Figueiredo et al., 2013).

According to the results presented in this review, there was a predominance of studies that use low-power laser as an effective alternative in the prevention and treatment of oral mucositis induced by chemotherapy and / or radiotherapy (Florentino et al., 2015).

Another therapy used with good clinical results was the use of Palifermin (keratinocyte growth factor) to prevent and treat $\mathrm{OM}$ in patients undergoing chemotherapy and radiotherapy (Ribeiro et al., 2008; Santos et al., 2009; Miranda et al 2016; Daugèlaite et al., 2019). It is approved in Europe and the USA to reduce the 
incidence of OM in hematological malignancies (Albuquerque et al., 2007). According to the studies presented by Daugelaite et al. (2019), Palifermin used in smaller doses (60ug / kg) had no significant result in comparison to that used in larger doses (180ug / $\mathrm{kg}$ ). Ribeiro et al. (2008), cites Palifermin as a new therapeutic option to prevent oral mucositis, recommending a dose of $60 \mathrm{ug} / \mathrm{kg} /$ day for three days before treatment and three days after autologous stem cell transplantation. Miranda et al. (2016), showed that the use of Palifermin reduced the occurrence of severe oral mucositis in patients receiving high doses of chemotherapy and radiation therapy.

The use of mouthwash is mentioned in almost all studies, and it was observed that there are controversies regarding the use of $0.12 \%$ chlorhexidine, which should continue to be researched to prove its effectiveness and ensure a correct prescription. However, even in the face of disagreements regarding its use, it is still on the list of most used substances for mouthwash, in helping to prevent and treat OM. In addition to chlorhexidine, mouthwashes with sodium bicarbonate diluted in water and some natural agents, such as mallow tea, chamomile, sage, myrrh, are also mentioned. All have antimicrobial action, but natural agents have the advantages of not causing dysgeusia, not staining your teeth and not causing burning. Things that happen with the use of chlorhexidine (Albuquerque et al., 2007; Santos et al., 2009; Ribeiro Júnior et al., 2010; Miranda et al., 2016).

In most cases, $\mathrm{OM}$ is accompanied by opportunistic infections. Candidiasis is the most common, so it is almost always associated with the treatment the use of antifungals, applied in different forms of administration, depending on the degree of mucosal involvement (Ribeiro Júnior et al., 2010).

\section{FINAL CONSIDERATIONS}

For everything reported in this literature review, the importance of the presence of the dentist in the team involved with the patient in an outpatient and hospital environment is reinforced. This is due to its important role both in the pre and post treatment of patients, since the success in the management of oral complications of antineoplastic therapy involves preventive consultations, thus avoiding sequels of chemotherapy and radiotherapy. Finally, it is noteworthy that the low-power laser used 
in the prevention and treatment of mucositis, presents itself as a viable option, of low cost and without side effects.

\section{REFERÊNCIAS}

1. Marques ECP, Lopes FP, Nascimento IC, Morelli J, Pereira MV, Meiken VMM, Pinheiro SL. Photobiomodulation and photodynamic therapy for the treatment of oral mucositis in patients with cancer. Photodiagnosis and Photodynamic Therapy. 2020Mar;29.

2. Ribeiro Júnior O, Borba AM, Guimarães Júnior J. Prevenção e tratamento da mucosite bucal: o papel fundamental do cirurgião-dentista - Revisão. Rev Clín Pesq Odontol, Curitiba. 2010Jan./Abr;6(1):57-62.

3. Daugèlaitė G, Užkuraitytė K, Jagelavičienė E, Filipauskas A. Prevention and treatment of chemotherapy and radiotherapy induced oral mucositis. Medicina, Kaunas. 2019;55(2):25.

4. Hong CHL; Gueiros LA; Fulton JS, Cheng KKF, Kandwal A, Galiti D. Systematic review of basic oral care for the management of oral mucositis in cancer patients and clinical practice guidelines. Support Care in Cancer. 2019 Oct;27(10):3949-3967.

5. Santos PSS, Messaggi AC, Mantesso A, Magalhães MHCG. Mucosite oral: perspectivas atuais na prevenção e tratamento. RGO, Porto Alegre. 2009Jul./Set;57(3):339-344.

6. Menezes AC, Rosmaninho E, Raposo B, Alencar MJS. Abordagem clínica e terapêutica da mucosite oral induzida por radioterapia e quimioterapia em pacientes com câncer. Rev Bras Odontol, Rio de Janeiro. 2014Jan/Jun;71(1):35-38.

7. Ribeiro RA, Leitão RFC, Sant'ana RO, Moura JFB, Lima V, Medeiros RP et al. Mucosite oral: patogênese e manuseio clínico. Rev Bras Oncologia Clínica. 2008 Set./Dez;5(15):18-24.

8. Miranda SS, Queiroz LR, Freitas VS. Prevenção e tratamento das mucosites orais: uma revisão sistemática. Rev Saúde Col UEFS, Feira de Santana. 2016Dez;6(2):66-73.

9. Oliveira EL, Cabral GMP, Galvão AKFC, Pedrine JAGD, Silva, MCVS, Dantas MAPD. Mucosite - uma revisão sistemática. Revista Campo do Saber. 2018Out/Nov;4(5):16-34.

10. Florentino ACA, Macedo DR, David EF, Carvalho K, Guedes CCFV. Tratamento da mucosite oral com laser de baixa potência: revisão sistemática de literatura. Rev Ciênc Méd, Campinas. 2015Mai./Ago;24(2):85-92. 
11. Albuquerque ILS, Camargo TC. Prevenção e tratamento da mucosite oral induzida por radioterapia: revisão de literatura. Revista Brasileira de Cancerologia. 2007;53(2): 195-209.

12. Florentino ACA, Macedo DR, David EF, Carvalho K, Guedes CCFV. Utilização da terapia com laser de baixa potência para prevenção de mucosite oral: revisão de literatura. Rev Ciênc Méd, Campinas. 2015Mai./Ago;24(2):85-92.

13. Garcez AS, Ribeiro MS, Núñez SC. Laser de baixa potência: princípios básicos e aplicações clínicas na odontologia. Saunders: Elsevier Editora Ltda; 2012. P. 472.

14. Lopes LD, Rodrigues AB, Brasil DRM, Moreira MMC, Amaral JG, Olivira PP. Prevenção e tratamento da mucosite em ambulatório de oncologia: uma construção coletiva. Texto Contexto Enferm. 2016;25(1):e2060014.

15. Cardoso MFA, Novikoff S, Tresso A, Segreto RA, Servantes O. Prevenção e controle das sequelas bucais em pacientes irradiador por tumores de cabeça e pescoço. Radiol Bras. 2005;38(2):107-115.

16. Pacheco JA. Successful management of dysgeusia by photobiomodulation (PBM) in a cancer patient. 2019May.

17. Pacheco JA, Schapochnik A, Sá CC, Santiago ACM, Martinez GL, Yamaji MAK. Applied transdérmic photobiomodulator therapy about the primary carótide artery in patients under hormonal blockers and dynude disorders and pathogenic flora of orofaríngeo and systematic repercussions. Am J Biomed Sci \& Res. 2019:271-278.

18. Reolon LZ, Rigo L, Conto F, CÉ LC. Impacto da laserterapia na qualidade de vida de pacientes oncológicos portadores de mucosite oral. Rev Odontol. UNESP Araraquara. 2017Jan./Feb;46(1):1-9

19. Figueiredo ALP, Lins L, Cattony AC, Falcão AFP. Laser terapia no controle da mucosite oral: um estudo de metanálise. Rev Assoc Med Bras, São Paulo. 2013Sept./Out;59(5):467-474.

20. Valduga F, Oltramri E, Lemes LTO, Mattos CE, Stefenon L, Mozzini CB. Prevenção da mucosite oral em pacientes submetidos à quimioterapia. Revista Brasileira de Cancerologia. 2018;64(2):189-194. 